\title{
Peripheral Cemento-ossifying Fibroma: A Report of Two Cases
}

\author{
${ }^{1}$ Sanjeela R Guru, ${ }^{2}$ Sinam S Singh, ${ }^{3}$ Rakshith C Guru
}

\begin{abstract}
Peripheral cemento-ossifying fibroma (PCOF) is an osteogenic neoplasm of odontogenic origin with uncertain pathogenesis, which presents as a localized growth manifesting predominantly in adolescent and young adults. Early diagnosis by thorough radiographic and histologic examination is crucial for positive identification of lesions. Proper surgical excision with aggressive curettage of adjoining tissues and complete elimination of etiological factors is extremely important for prevention of recurrence. This clinical report presents two cases of patients who reported with localized gingival overgrowth, diagnosed as PCOF after histological examination. The clinical, radiographic, and histologic features of the two cases are discussed, and postsurgery, the patients have been followed up for a 1-year period with no recurrence. In conclusion, it is difficult clinically to differentiate between the various gingival lesions. Therefore, this article emphasizes that though recurrence rate of $\mathrm{PCOF}$ is high, most of these cases can be adequately managed with sound periodontal treatment.
\end{abstract}

Keywords: Gingiva, Gingival overgrowth, Peripheral cementoossifying fibroma.

How to cite this article: Guru SR, Singh SS, Guru RC. Peripheral Cemento-ossifying Fibroma: A Report of Two Cases. J Health Sci Res 2016;7(2):71-75.

Source of support: Nil

Conflict of interest: None

\section{INTRODUCTION}

The periodontal structures may be affected by a large variety of local and systemic lesions and disorders. Majority of these localized gingival lesions are plaque related and typically represent "reactive proliferative lesions" rather than true neoplasms. ${ }^{1,2}$ Peripheral cemento-ossifying fibroma (PCOF) is one such lesion accounting for about $3.1 \%$ of all oral tumors and $9.6 \%$ of gingival lesions. ${ }^{3}$ Peripheral

\footnotetext{
${ }^{1}$ Reader, ${ }^{2}$ Assistant Professor, ${ }^{3}$ Professor

${ }^{1}$ Department of Periodontics, Vydehi Institute of Dental Sciences and Research Centre, Bengaluru, Karnataka, India

${ }^{2}$ Department of Periodontics, Dental College, Regional Institute of Medical Sciences, Imphal, Manipur, India

${ }^{3}$ Department of Prosthodontics, Vydehi Institute of Dental Sciences and Research Centre, Bengaluru, Karnataka, India

Corresponding Author: Sanjeela R Guru, Reader, Department of Periodontics, Vydehi Institute of Medical Sciences and Research Centre, Bengaluru, Karnataka, India, e-mail: sanjeelaguru@yahoo.co.in
}

cemento-ossifying fibromas have been described in the literature since the 1940s, but it was Waldron who established it as a benign fibro-osseous lesion. ${ }^{4}$ The 1992 World Health Organization (WHO) classification included it in the group of nonodontogenic tumors as a single designation of cemento-ossifying fibroma (COF) with two histologic types, which are difficult to distinguish. ${ }^{5}$ A variety of names have been used to describe these fibroblastic calcifying gingival lesions, suggesting the dispute surrounding their classification., ${ }^{5,6}$ Cemento-ossifying fibroma is considered a rare osteogenic tumor (nonodontogenic) with variable expressiveness. This article reports two cases of PCOF, which after surgical excision have been followed up for a period of 1 year with no recurrence.

\section{CASE REPORTS}

\section{Case 1}

A 24-year-old female reported to the Department of Periodontics with the chief complaint of painless swelling in the gums in the lower front tooth region of the jaw since 1 year. Initially, patient noticed a small swelling on the labial gingiva in 41 and 42 region, which gradually increased to the present size causing difficulty in mastication and lip approximation. The patient presented with no significant contributing medical history.

Gingival examination revealed a large solitary pedunculated gingival mass measuring $3.5 \times 2 \mathrm{~cm}$, located on the labial gingiva in the interdental papilla between 41 and 42 (Fig. 1). The overlying mucosa appeared pink

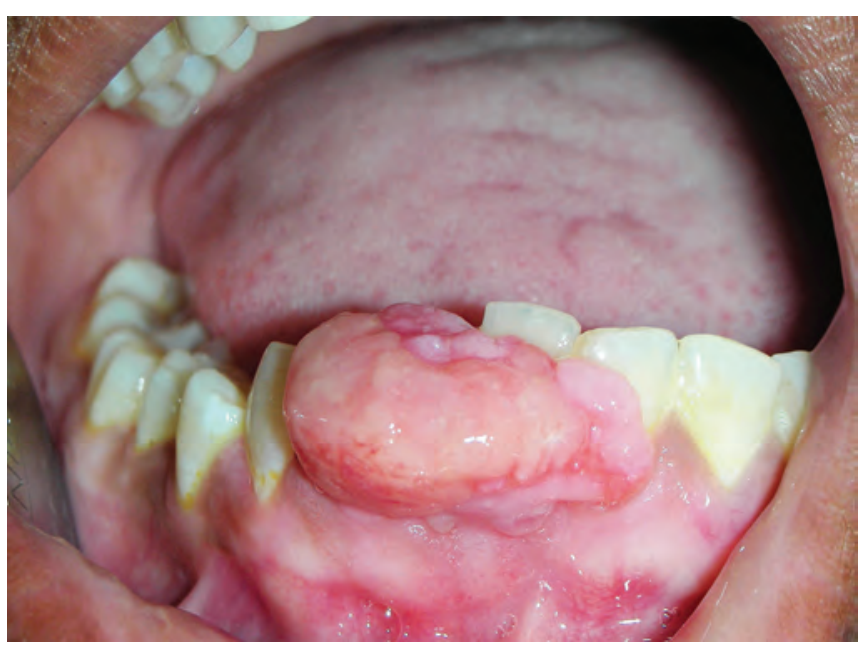

Fig. 1: Preoperative photo showing gingival overgrowth anterior view 


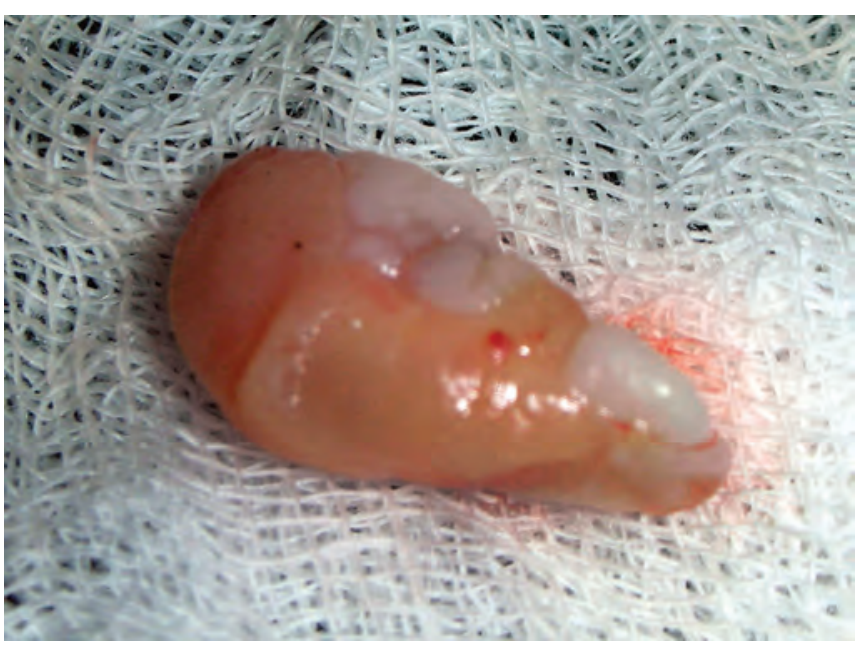

Fig. 2: Excisional biopsy

and lobulated. The swelling was firm in consistency and nontender, and there was no bleeding on palpation. Pathologic migration of 41 and 42 was noted probably because of excessive pressure from the gingival growth, as evaluation of occlusion did not reveal any trauma from occlusion between the maxillary and mandibular anterior teeth. Both 41 and 42 presented with Grade I mobility. Periodontal examination did not reveal any other significant findings.

The mandibular occlusal radiograph revealed a soft tissue shadow with diffuse radiopacities extending from 31 to 42. Intraoral periapical (IOPA) radiograph revealed only mild crestal bone loss in the interdental area between 41 and 42; however, the diffuse radiopacities were not well appreciated in the IOPA.

The overgrowth was provisionally diagnosed as peripheral ossifying fibroma. Differential diagnosis of pyogenic granuloma and peripheral giant cell granuloma was also given.

Oral prophylaxis was performed, and oral hygiene instructions (OHIs) were given. One week later, excisional biopsy was done under local anesthesia (LA) (Fig. 2). The adjacent teeth were scaled to remove any residual local irritants, and thorough curettage of gingival tissues was performed. The excised tissue was submitted for histopathological analysis. Histopathological diagnosis was PCOF.

The surgical site appeared to be healing well on the 10th day postoperatively. Patient was followed up at regular intervals, and oral hygiene was reinforced (Fig. 3). No recurrence was noted on the 12th month follow-up visit (Fig. 4).

\section{Case 2}

A 25-year-old female reported to the Department of Periodontics with the chief complaint of a painless

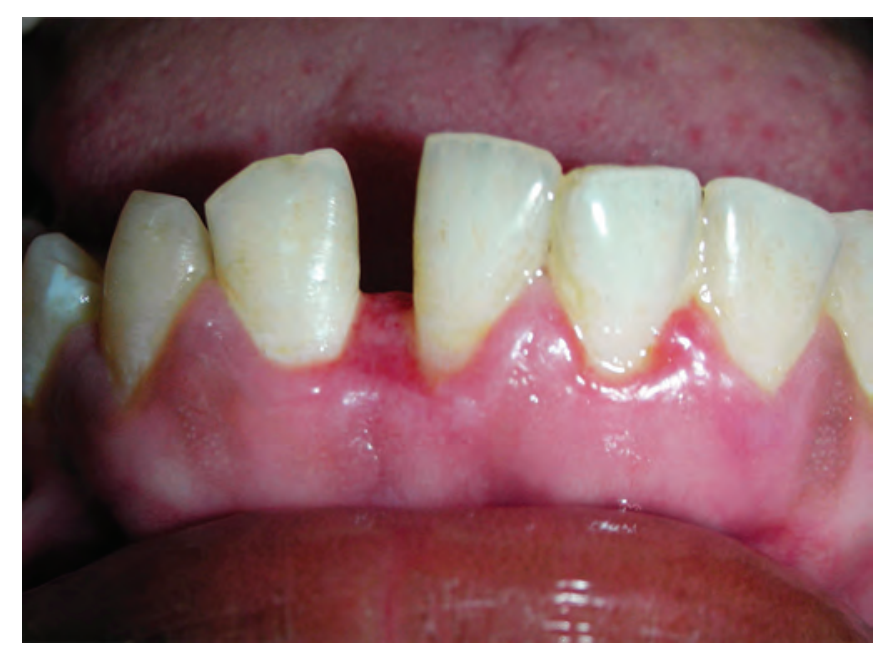

Fig. 3: Six months follow-up photo - anterior view

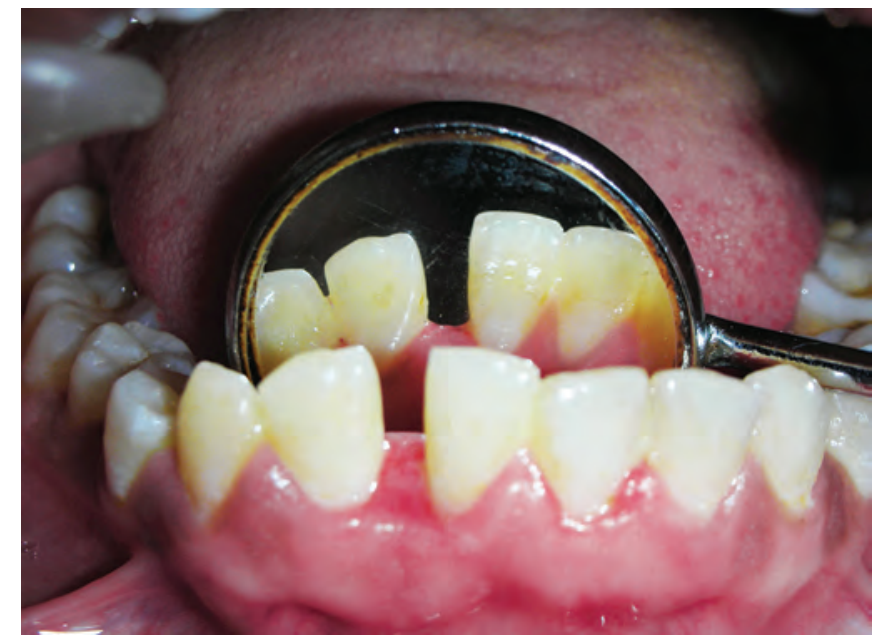

Fig. 4: Twelve months follow-up photo - anterior view

swelling in the gums in relation to lower front tooth region of the jaw since 2 years. The patient also complained of difficulty in mastication and displacement of the mandibular anterior teeth.

The patient noticed a small swelling in the interdental gingiva between 31 and 41, which gradually increased to the present size over a period of 2 years. Bleeding while brushing and difficulty in mastication were experienced as the swelling had increased in size to involve incisal edges of 31 and 41. Migration of mandibular anterior teeth was also noted.

Gingival examination revealed a diffuse, lobulated sessile gingival overgrowth measuring approximately $1 \mathrm{~cm}$ mesiodistally and about $2.5 \mathrm{~cm}$ buccolingually in the interdental papilla region between 31 and 41 and extending both buccally and lingually. The gingival overgrowth covered almost two-thirds of tooth structure of 31 and 41 and was more pronounced on the lingual aspect (Figs 5A and B) than buccal. The overlying mucosal surface appeared pinkish in color with erythematous patches. The lesion was firm in consistency 

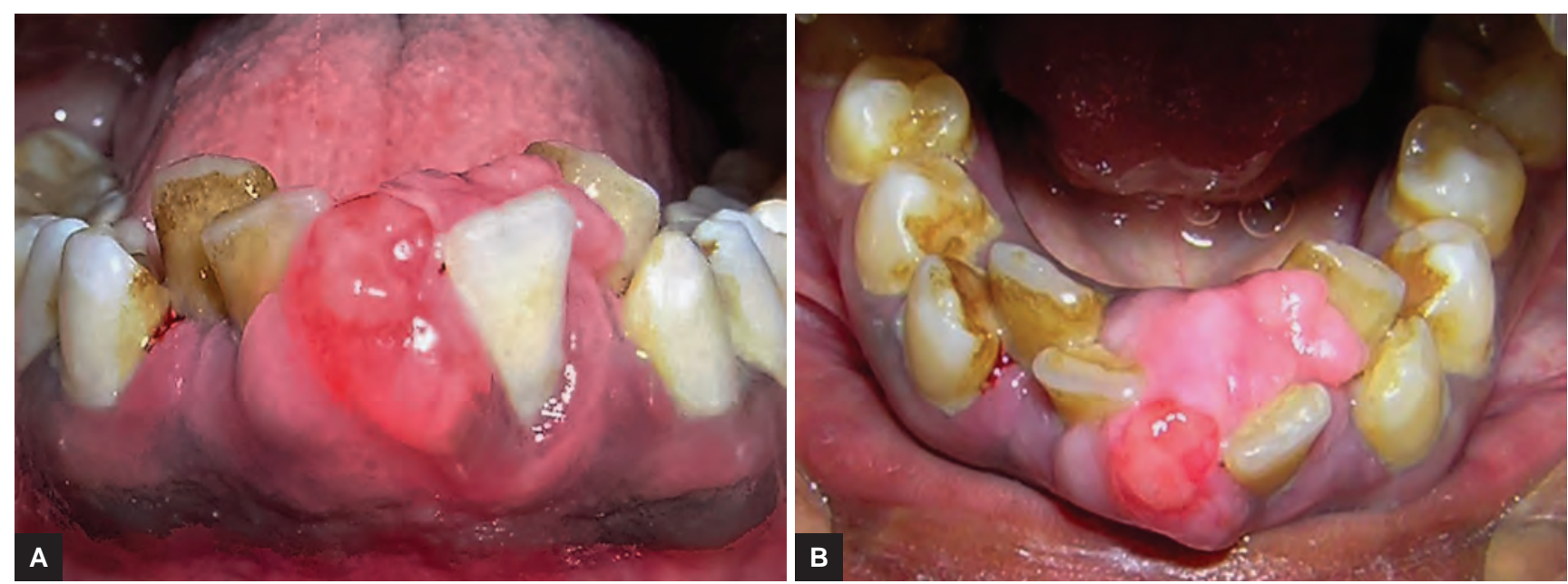

Figs 5A and B: (A) Preoperative photo showing gingival overgrowth - anterior view; and (B) Preoperative photo showing gingival overgrowth - occlusal view

but was edematous in areas, which appeared reddish in color. Bleeding on probing and grade I mobility with 31 was detected.

Mandibular occlusal radiograph revealed only a soft tissue shadow extending from tooth 32 to 41 . Intraoral periapical radiograph showed mild crestal bone loss between 31 and 41 (Fig. 6).

A provisional diagnosis of peripheral giant cell granuloma and differential diagnosis of pyogenic granuloma, fibroma, and peripheral ossifying fibroma was established.

After routine blood investigations and informed consent, oral prophylaxis was performed, and OHIs were given. One week later, lesion was completely excised under LA. Adjacent teeth were scaled, and thorough curettage of underlying tissues was also done. The excisional biopsy was submitted for histopathological analysis (Fig. 7), which revealed that it was PCOF.

The patient presented for follow-up examination 7 days postoperatively and surgical site appeared to be

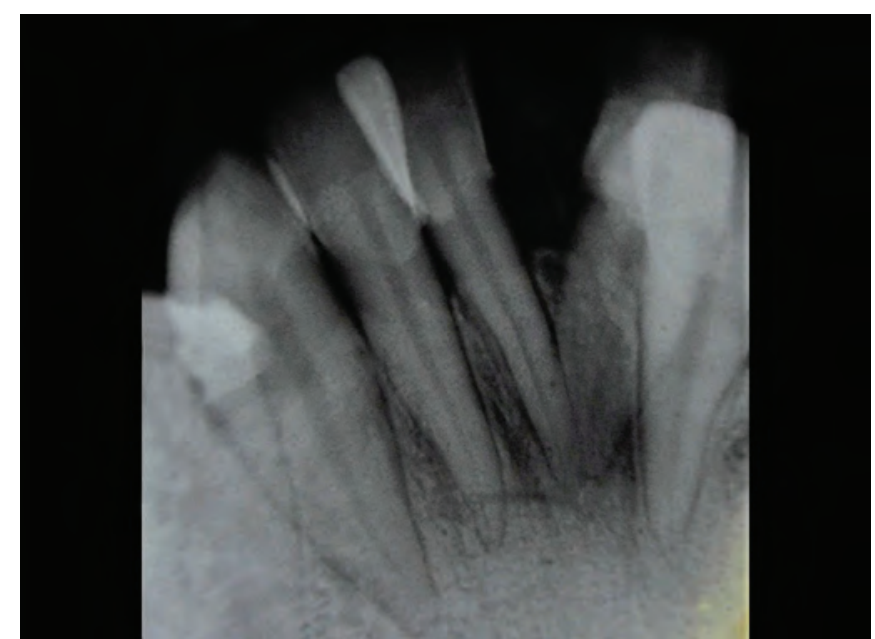

Fig. 6: Intraoral periapical radiograph healing well. The patient was followed up for a period of 1 year with no recurrence (Figs 8 and 9).

\section{Histopathological Examination}

Both the biopsy specimens showed similar histopathological findings. Histopathology examination revealed ulcerated parakeratinized, stratified squamous epithelium overlying fibrocellular connective tissue (Fig. 10A). The cellular connective tissue presented with chronic inflammatory cell infiltrate in areas of ulceration, numerous dilated blood vessels, minimal collagen fibers, few multinucleated giant cells, and numerous foci of cementum-like calcified masses of varying size (Fig. 10B).

\section{DISCUSSION}

Peripheral cemento-ossifying fibroma is a well-demarcated and occasionally encapsulated lesion. It consists of fibrous tissue with variable amounts of calcific material resembling bone (ossifying fibroma), cementum (cementifying fibroma), or both. ${ }^{4}$ Gingival lesions are

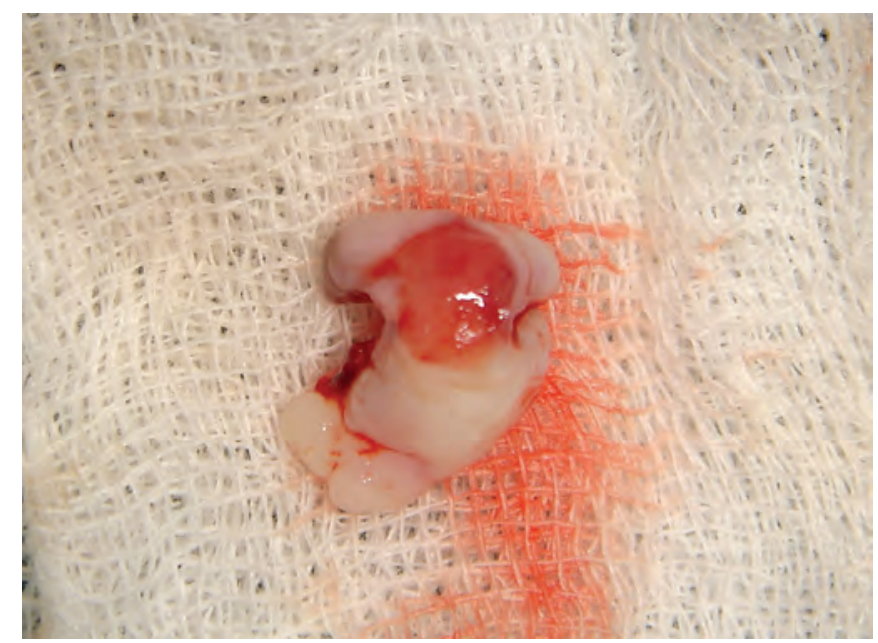

Fig. 7: Excisional biopsy 


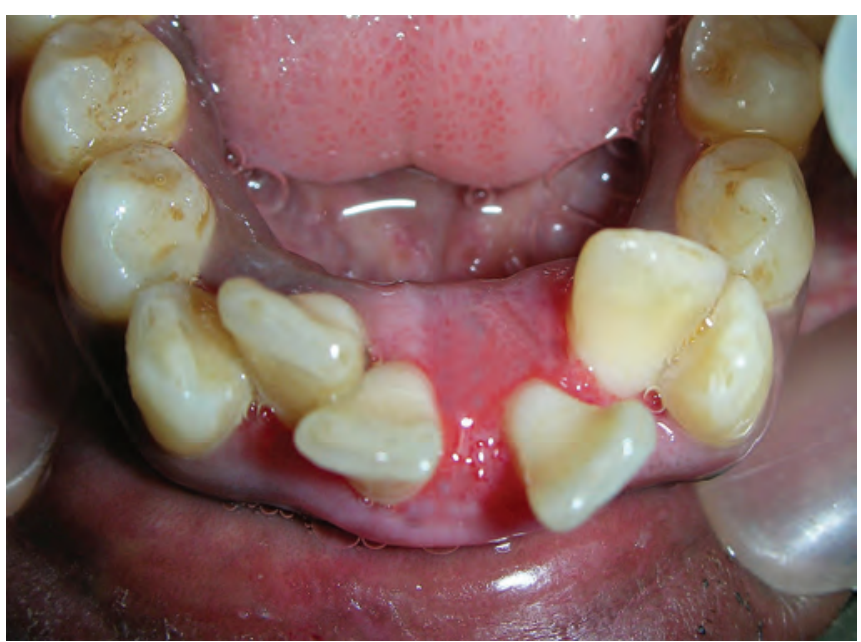

Fig. 8: Six months follow-up photo - occlusal view

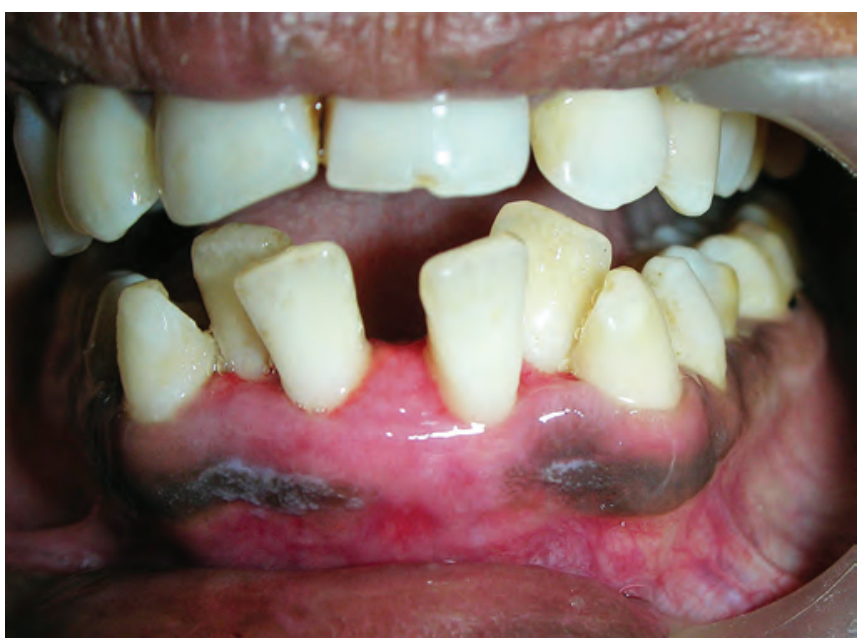

Fig. 9: One year follow-up photo -anterior view

rare compared with lesions that appear within bone. ${ }^{7}$ Although etiopathogenesis of PCOF is still unclear, it has been suggested that these lesions originate from cells of periodontal ligament. ${ }^{6,8}$ Peripheral cemento-ossifying fibroma is often associated with local irritants, such as subgingival plaque, calculus, or trauma from dental appliances and poor-quality dental restorations. ${ }^{9}$ Certain common diagnostic clinical features of PCOF have been previously outlined. ${ }^{10,11}$ Peripheral cemento-ossifying fibroma is more predominantly seen in women, ${ }^{3}$ with peak incidence between 2 nd and 3rd decades, ${ }^{10,12}$ suggesting that hormonal influences may play a role. About $60 \%$ of tumors occur in maxilla, with anterior gingiva being most commonly involved. Clinically, PCOF is a slow-growing gingival mass measuring less than $2 \mathrm{~cm}$ in size and located more commonly in interdental gingiva. ${ }^{1,10,13}$ It may be sessile or pedunculated, identical in color to that of gingiva or slightly reddish, and may have an ulcerated surface. Peripheral cemento-ossifying fibroma is more firm and less friable than other lesions and generally has a longer course, which explains the

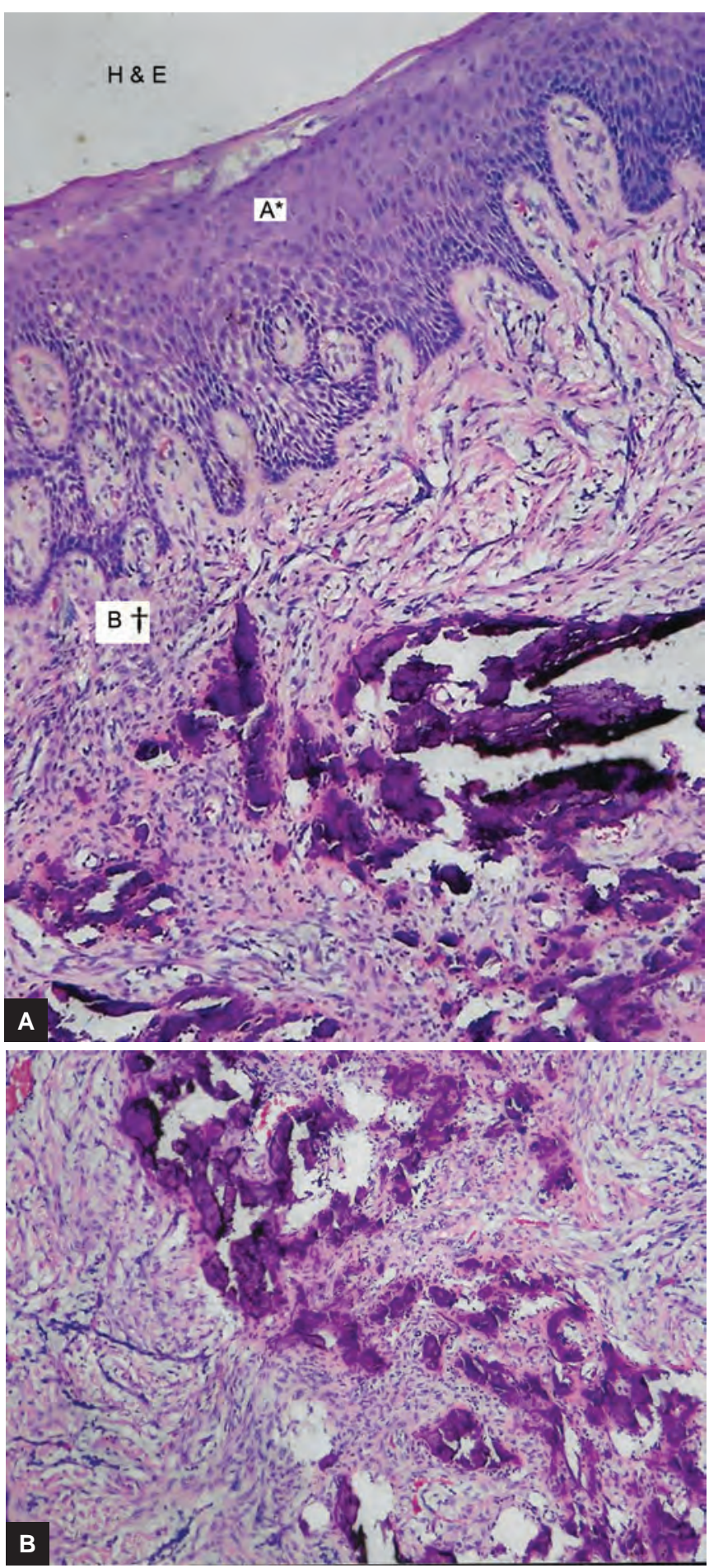

Figs 10A and B: (A) Photomicrograph of hematoxylin and eosinstained histological section; and (B) Connective tissue showing few multinucleated giant cells and numerous foci of cementum-like calcified masses. *Parakeratinized, stratified squamous epithelium. ${ }^{\dagger}$ Superficial connective tissue showing dense inflammatory cell infiltrate

calcification and/or ossification. ${ }^{8}$ Radiographically, some, but not all lesions, may show foci of calcifications scattered in the central area of the lesion. Radiographs usually do not reveal any underlying bone involvement but rarely superficial erosion of bone may be seen. ${ }^{14}$ Histological examination is imperative for definitive 
diagnosis, which is based on focal presence of bone or other calcifications in cellular connective tissue. ${ }^{8,15}$ This emphasizes the need for histopathological examination of biopsy specimen for an accurate diagnosis because of difficulty in diagnosing PCOF based only on clinical observations. Treatment of PCOF consists of removal of etiological factors, scaling adjacent teeth, and aggressive surgical excision. Some authors have suggested excision of involved periodontal ligament and periosteum to minimize the possibility of recurrence of incompletely removed lesions. ${ }^{14}$ Peripheral cemento-ossifying fibroma reportedly has high recurrence rate of approximately $20 \%$, hence long-term postoperative follow-up is imperative. ${ }^{15}$ The recurrence has been attributed to incomplete initial removal, repeated injury, and/or the persistence of the local irritants. ${ }^{15}$ Most of the above-mentioned clinical and specific histopathological features of PCOF correlated with our cases. The lesions were successfully treated, and both the patients were followed up for a 1 year period with no recurrence probably because a wide excision of the lesion was done, and thorough curettage of the underlying tissues was done.

\section{CONCLUSION}

Peripheral cemento-ossifying fibroma is a slowly progressing non-neoplastic lesion, the growth of which is generally limited. However, since the lesions are asymptomatic, many cases may progress for long periods before patients seek treatment. Postoperative follow-up is required because of $20 \%$ recurrence rate.

\section{REFERENCES}

1. Bhaskar SN, Levin MP. Histopathology of the human gingiva (study based on 1269 biopsies). J Periodontol 1973 Jan;44(1):3-17.
2. Van der Waal I. Non-plaque related periodontal lesions. An overview of some common and uncommon lesions. J Clin Periodontol 1991 Jul;18(6):436-440.

3. Kenney JN, Kaugars GE, Abbey LM. Comparison between the peripheral ossifying fibroma and peripheral odontogenic fibroma. J Oral Maxillofac Surg 1989 Apr;47(4):378-382.

4. Waldron CA. Fibro-osseous lesions of the jaws. J Oral Maxillofac Surg 1993;51:828-835.

5. Gardner DG. The peripheral odontogenic fibroma: an attempt to clarification. Oral Surg Oral Med Oral Pathol 1982 Jul;54(1):40-48.

6. Zain RB, Fei YJ. Fibrous lesions of the gingiva: a histopathologic analysis of 204 cases. Oral Surg Oral Med Oral Pathol 1990 Oct;70(4):466-470.

7. Endo Y, Uzawa K, Mochida Y, Nakatsuru M, Shiiba M, Yokoe H, Yamauchi M, Tanzawa H. Differential distribution of glycosaminoglycans in human cementifying fibroma and fibro-osseous lesions. Oral Dis 2003 Mar;9(2):73-76.

8. Neville, B.W.; Damm, D.D.; Allen, C.M.; Bouquot, J.E. In: Text book of oral and maxillofacial pathology. 2nd ed. Philadelphia: W.B. Saunders Co; 2004. pp. 451-452.

9. Batsakis, J.G. Non-odontogenic tumors: clinical evaluation and pathology. In: Thawley, S.E.; Panje, W.R.; Batsakis, J.G.; Lindberg, R.D., editors. Comprehensive management of head and neck tumors. 2nd ed. Philadelphia: W.B. Saunders Co; 1999. p. 1641-1642.

10. Marx, R.E.; Stern, D. In: Oral and maxillofacial pathology: a rationale for diagnosis and treatment. Chicago: Quintessence; 2003. pp. 23-25.

11. Kumar SK, Ram S, Jorgensen MG, Shuler CF, Sedghizadeh PP. Multicentric peripheral ossifying fibroma. J Oral Sci 2006 Dec;48(4):239-243.

12. Zhang W, Chen Y, An Z, Geng N, Bao D. Reactive gingival lesions: a retrospective study of 2,439 cases. Quintessence Int 2007 Feb;38(2):103-110.

13. Eversole LR, Leider AS, Nelson K. Ossifying fibroma: a clinicopathologic study of sixty-four cases. Oral Surg Oral Med Oral Pathol 1985 Nov;60(5):505-511.

14. Kendrick F, Waggoner WF. Managing a peripheral ossifying fibroma. ASDC J Dent Child 1996 Mar-Apr;63(2):135-138.

15. Cuisia ZE, Brannon RB. Peripheral ossifying fibroma-a clinical evaluation of 134 pediatric cases. Pediatr Dent 2001 May-Jun;23(3):245-248. 